\title{
Tecnologia Assistiva de Vivências Musicais na recuperação vocal de idosos portadores de Doença de Parkinson*
}

\author{
Assisted Technology in musical life experiences for vocal recovery of \\ aged people carrying Parkinson's Disease \\ Edméia Campos Meira ${ }^{0}$ \\ Edite Lago da Silva Sena \\ Andréa dos Santos Souza \\ Virgínia Maria Mendes Oliveira Coronago ${ }^{d}$ \\ Lucia Hisako Takase Gonçalves ${ }^{e}$ \\ Elienai Teixeira dos Santos ${ }^{f}$ \\ Ana Alice da Silva Bôa Sorte ${ }^{9}$ \\ Lorena Teixeira Santos ${ }^{h}$
}

\section{Resumo}

A tecnologia de vivências musicais desenvolvida e testada teve o objetivo de avaliar sua efetividade em termos de recuperação vocal de idosos parkinsonianos. A metodologia desenvolvida em Jequié (BA), no campus da UESB, envolveu uma amostra de 12 idosos selecionados por conveniência e que se submeteram aos procedimentos de teste e avaliação da tecnologia por um período de dois semestres de 2007. A tecnologia foi avaliada aplicando-se, no pré e pós-vivências musicais, instrumentos de avaliação de aprimoramento vocal. A tecnologia se constituiu de teste da vOz, cujo treinamento incluía atividades rítmicas corporais, técnicas vocais de aquecimento vocal, técnica de respiração diafragmática e intercostal, práti-

Palavras-chave:

Musicoterapia.

Equipamentos de auto-ajuda. Melhoramento Biomédico. Voz. Idoso fragilizado. Doença de Parkinson. Jequié (BA) ca de canto em grupo. Resultados: a maioria dos idosos demonstrou melhoras na emissão vocal. Metade demonstrou melhoras na dinâmica respiratória, no aumento do número de notas cantadas em uma inspiração e articulação nos vocalizes. Outros demonstraram melhoras na performance vocal, seja no desenvolvimento da postura na emissão da voz, seja na articulação dos vocalises. Mesmo os que não obtiveram melhoras, conservaram-se em seu estado anterior sem progressão da doença por um ano, enquanto praticavam as vivências. Os achados levaram-nos a concluir pela efetividade da dita tecnologia de vivências musicais como promotora da inclusão social dos idosos parkinsonianos.

\footnotetext{
Universidade Estadual do Sudoeste da Bahia

Departamento de Saúde

Jequié, BA, Brasil

Correspondência / Correspondence

Edméia Campos Meira

$\mathrm{UESB} / \mathrm{DS}$

Rua Gonçalves da Costa, 128 - Jequiezinho

45200-000 - Jequié, BA, Brasil

E-mail: edmeiameira@yahoo.com.br

* Parte do projeto interinstitucional de pesquisa: Tecnologia Assistiva para Autonomia e Inclusão Social de Idoso Portador da Doença de Parkinson - TAIP. Convênio UFSC-PEN/GESPI x UESB-DS/GREPE, Ref. 2183/05, subvencionado pela FINEP - Financiadora de Estudos e Projetos, Ministério da Ciência e Tecnologia (Chamada Pública MCT/FINEP/AT - Tecnologias Assistivas - 09/2005).
} 


\section{Abstract}

The technology of musical experiences developed and tested aimed to evaluate its effectiveness in terms of vocal recovery of senior Parkinsonians. Methodology was developed in Jequié, Bahia State, at the UESB campus. It involved a sample of 12 seniors selected by convenience who underwent test procedures and evaluation of the technology for a period of two semesters in 2007. The technology has been evaluated through application, on pre and post musical experiences, instruments to evaluate vocal improvement. It consisted of voice testing and included: corporal rhythmic activities, vocal techniques for vocal warm up,

Key words: Music Therapy. Self-help devices. Biomedical Enhancement. Voice. Frail elderly. Parkinson Disease. Jequié city(BA) diaphragmatic and intercostal breathing techniques, singing practice in groups. Results: most seniors showed improvements in vocal emissions. Half of them showed improvements in breathing dynamics, increased the number of singing notes in an inspiration and vocalizes articulation. Others demonstrated improvements in vocal performance, not only in postural development in voice emission but also in their vocalizes articulation. Even those who did not obtain any improvement kept their previous state without disease progression for one year, while they practiced the experiences. The discoveries made us think about the effectiveness of musical experiences technology in promoting social inclusion from senior Parkinsonians.

\section{INTRODUÇÃO}

O crescimento da população idosa nos últimos anos reflete um aumento significativo na prevalência de doenças crônico-degenerativas, o que tem interferido na morbidade e mortalidade da população. Dentre as doenças que acompanham a velhice, está a Doença de Parkinson (DP), que apresenta alta prevalência. Calcula-se, para o mundo inteiro, 10 milhões de pessoas portadoras. No Brasil esse número está em torno de 300.000 pessoas, ou seja, uma prevalência de 150 a 200 casos por 100.000 habitantes, com surgimento de 20 novos casos por ano. ${ }^{1}$

A DP é uma afecção crônica e progressiva do sistema nervoso cuja evolução dos sintomas é usualmente lenta. Envolve os gângli- os da base, resultando em perturbações no tônus, posturas anormais e movimentos involuntários, caracterizando-se clinicamente por rigidez, bradicinesia e tremor. Tal manifestação tem supostamente origem neuroquímica causada pela deficiência de dopamina, provocada por uma degeneração dos neurônios da substância negra. ${ }^{2-4}$

A voz e a fala também sofrem disfunções em decorrência da doença. Essas alterações constituem, em conjunto, o que se denomina disartria hipocinética ou disartrofonia, caracterizada por monotonia, redução da intensidade da voz, articulação imprecisa e distúrbio de ritmo, os quais decorrem de três fatores principais: restrições da freqüência e intensidade, redução da intensidade e alteração de qualidade. ${ }^{5,6}$ 
Assim, as dificuldades decorrentes na comunicação e expressão por alterações da fala, na deambulação e instabilidade de postura costumam ocasionar aumento no nível de ansiedade do paciente e, reforçada pelo estigma do envelhecimento, dificulta a manutenção de autoestima satisfatória. Em vista disto, observa-se a necessidade de instrumentos como de tecnologia assistida em vivências musicais para a manutenção e/ou aprimoramento da qualidade vocal dos parkinsonianos.

As práticas musicais contribuem na geração de atributos para a obtenção de uma autoestima satisfatória, despertando sentimentos de competência, confiança e de adequação à vida, com o desenvolvimento de uma melhor capacidade de compreensão, estimulando a auto-aceitação, pelo paciente, do processo natural do envelhecimento associado à DP. As vivências musicais realizadas em grupo proporcionam também o restabelecimento do equilíbrio emocional do indivíduo, uma vez que promovem ganhos na qualidade e ritmo da voz, melhoria da força motora e aprimoramento da capacidade de concentração, possibilitando independência intelectual, além de reinserção no meio social. ${ }^{7}$

No idoso portador de doença crônicoprogressiva, como a DP, a comunicação apresenta instabilidade, que podem ser decorrente de ajuste ao medicamento, frustração, ansiedade, depressão, cansaço e situações estressantes. Em vista disso, os indivíduos se utilizam da comunicação não-verbal aprendida ao longo da vida, como "expressões faciais, do corpo, da postura fisica, a distância mantida entre as pessoas; a capacidade e o jeito de tocar; da roupa que usa". ${ }^{8}$ Essa comunicação não-verbal pode ser traduzida em emoções musicais que proporcionam a integração social em determinada cultura, melhorando o bem-estar geral. A música, com seus efeitos fisiológicos, age em determinadas áreas do cérebro, a exemplo do sistema límbico, que atua preferencialmente no controle das atividades emocionais e comportamentais. $^{8}$

A música tem sido utilizada como recurso promotor de bem-estar e qualidade de vida, permeando diferentes culturas e gerações. Associada à medicina, era uma das alternativas de tratamento durante os rituais de cura, além de estar presente em outros rituais, como o de fecundidade, nascimento e até de morte. Ela pode condicionar o indivíduo a um estado de prazer, saudosismo e introspecção, agindo nas suas faculdades intelectuais e emocionais. Isto pode ser decorrente das semelhanças existentes entre os sons emitidos pelo corpo humano, como aqueles produzidos por instrumentos musicais. ${ }^{9,10}$

Assim, a música se caracteriza como uma linguagem universal, ela tem importância terapêutica e estimula a saúde mental do indivíduo, desviando sua atenção da problemática em que se encontra. ${ }^{11,12}$ Por meio de atividades musicais, é possível evitar e/ou reduzir fatores estressantes, haja vista a eficiência da música não apenas no alívio da dor, como também de distúrbios psicossomáticos, físicos e espirituais, graças à liberação de substâncias químicas cerebrais que podem atuar na regulação do humor, redução da agressividade, depressão e melhora do sono., ${ }^{9,13,14}$ 
A partir das considerações apresentadas, este estudo teve como objetivo geral desenvolver, adaptar e testar uma tecnologia assistiva/cuidada, valendo-se dos preceitos musicais específicos, visando ao aprimoramento da dicção e expressão oral; à coordenação motora e habilidade rítmica; ao aumento da percepção auditiva; à dinâmica respiratória e à oportunização de momentos de descontração, criatividade e socialização.

\section{METODOLOGIA}

A tecnologia de vivências musicais desenvolvida neste estudo, para a recuperação vocal de pacientes idosos parkinsonianos, teve fundamento no referencial teórico adotado a partir da compreensão de tecnologia assistiva/cuidada como sendo toda e qualquer experiência de atendimento profissional sistematizado, inventada para situação de serviços novos, ou reinventada para serviços que requerem adaptação e atualização. O entendimento de tecnologia assistida aqui adotada é a concepção de tecnologias leve e leve/dura, ${ }^{15}$ as quais diferem das convencionais, do tipo produção de equipamentos e máquinas. Trata-se de produção de tecnologia que expressa de modo exclusivo o trabalho vivo em ato - neste caso, as vivências musicais idealizadas e implementadas.

\section{Procedimentos metodológicos}

Conforme previsto no projeto, a implementação do estudo se deu a partir das seguintes etapas: desenho da tecnologia assistida de vivências musicais; teste-piloto para aprimoramento do desenho construído; implementação propriamente dita da tecnologia. Para avaliar a efetividade da tecnologia testada, foi aplicado um instrumento próprio elaborado com base nos elementos musicais estruturados, para verificar o desempenho da voz falada e da voz cantada. Quanto ao que foi construído para a avaliação da voz, incluíram-se itens como a emissão vocal, considerando o volume e o ritmo de voz falada e cantada, a dinâmica respiratória baseada em número de notas musicais cantadas a uma só inspiração e articulação nos vocalizes, a performance vocal associada ao desenvolvimento da postura na emissão da voz.

\section{Campo do estudo}

O estudo de natureza interinstitucional teve seu projeto aplicado em dois contextos: Florianópolis-SC (sede UFSC/PEN/GESPI) e Jequié-BA (UESB/DS/GREPE). O presente relatório refere-se ao realizado em Jequié, $\mathrm{BA}$, no campus universitário da Universidade Estadual do Sudoeste da Bahia, Departamento de Saúde - UESB/DS.

O município de Jequié localiza-se no sudeste da Bahia, a $360 \mathrm{~km}$ da capital, com território de $3.035 \mathrm{~km}^{2}$ e 148.186 habitantes. Destes, 13.178 são idosos, o que representa 9,5\% da população total, sendo que 7.193 estão entre as idades de 60 e 69 anos, 4.462 entre 70 a 79 anos e 2.523 com idade superior a 80 anos. $^{16}$

Em se tratando de idoso portador de Doença de Parkinson, as ações eram pratica- 
mente inexistentes no contexto estudado. Esse público começou a integrar-se em grupo e receber atenção a partir do projeto interinstitucional de pesquisa "Tecnologias Assistidas para a Autonomia e Inclusão Social de Idoso Portador da doença de Parkinson - TAIP”, sob a forma de projeto de extensão universitária denominado Grupo de Ajuda Mútua - GAM, do qual participaram pessoas portadoras de DP localizadas a partir de uma lista de pacientes que recebiam medicação específica para a doença, dispensada na Diretoria Regional de Saúde $\left(13^{a}\right.$, correspondente à Grande Jequié$\mathrm{BA})$ e entre aqueles pacientes que freqüentavam a Clínica de Fisioterapia da UESB/DS. O GAM se constituiu no lócus da pesquisa ao reunir potenciais participantes do estudo.

\section{População alvo e amostra}

A população-alvo se constituiu naquela formada por pacientes idosos portadores de DP localizados para a formação do GAM, anteriormente relatado. A amostra, de natureza intencional, foi composta de doze idosos que espontaneamente se apresentaram para participar do estudo assinando o Termo de Consentimento Livre e Esclarecido e que foram assíduos na participação das atividades grupais de vivencias musicais por dois semestres consecutivos no ano de 2007, com encontros semanais de duas horas.

\section{Desenvolvimento do desenho da tecnologia de vivências musicais}

As vivências musicais foram idealizadas e testadas compondo um conjunto de proce- dimentos técnicos baseados em um protocolo de avaliação a partir de referenciais da área da música testando a voz falada e cantada, e em cujo treinamento incluía: atividades rítmicas corporais; técnicas vocais com aquecimento vocal; técnica de respiração diafragmática e intercostal; pratica de canto em grupo; leitura de textos e letras de canções; prática de instrumento de sopro, sendo a flauta o instrumento adotado. Inicialmente foi necessário conhecer os interesses musicais dos participantes, compondo uma lista de gêneros de músicas preferenciais dos idosos. A seguir, apresentavam-se os procedimentos desenvolvidos junto aos portadores de DP em cada atividade indicada.

- Atividades rítmicas e corporais: exercícios de pulsação rítmica, observando as constâncias e inconstâncias dos andamentos musicais associados aos movimentos corporais. Observação das categorias de movimentos, visando a compará-los: o ritmo do andar, do falar, do cantar e do tocar. Observação das variantes rítmicas das músicas, associando-as ao ritmo dos movimentos corporais. Aplicação de exercícios rítmicos a partir de percussão corporal. Aplicação de exercícios rítmicos com instrumentos musicais de percussão.

- Atividades de técnicas vocais: autoconhecimento da $\mathrm{VOz}$ - alcance, potenciais expressivos, o som mais agudo, mais grave, mais leve, mais forte mais interrompido. Aplicação de vocalizes com as vogais, com pequenas frases musicais e notas musicais. Repetição de frases musicais com o acompanhamento do instrumento, utilizando sons ascendentes e descendentes da es- 
cala musical. Exercícios de dicção e impostação vocal: utilização de trava-línguas e textos rítmicos a partir de ditados populares. Exercícios cantados, utilizando a dinâmica da música: FF (forte), $\mathrm{mF}$ (meio forte), $\mathrm{P}$ (piano), $\mathrm{mP}$ (meio piano), pp (pianíssimo). Exercícios cantados para expansão dos limites vocais: entoação de diversas frases musicais em diferentes tonalidades. A fonação no canto: vibração (cordas vocais: ataque e finalização), articulação (emprego ideal dos fonemas), ressonância (variedades de ressonâncias da voz), saúde vocal.

\section{- Atividades técnicas de respiração:} exercícios respiratórios para emissão vocal, utilizando a respiração diafragmática e intercostal. Exercícios para aumentar o controle da respiração: inspiração e retenção do ar, contando mentalmente, seguido de expiração gradativa. Entoação de sons e notas musicais a uma só inspiração.

- Práticas de canto em grupo: execução de canções simples predeterminadas e de livre escolha pelo grupo. Estimulação da memória por meio de canções. Escuta de trechos musicais para identificação de variantes rítmicas e suas implicações no comportamento humano. Exercícios melódicos de concentração, sensibilidade auditiva, manutenção do volume e operacionalização da voz falada/cantada.

- Práticas do instrumento de sopro flauta doce: conhecimento do instrumento e suas possibilidades. Exercícios de posturas para emissão do som. Exercícios rítmicos associados a exercícios respiratórios. Aplicação de técnicas de respiração para sons curtos e longos. Conhecimento das figuras musicais: representação da nota musical. Exercícios de coordenação motora para a emissão do som no instrumento. Dinâmicas na execução dos sons: $\mathrm{FF}$ (forte), $\mathrm{mF}$ (meio forte), $\mathrm{P}$ (piano), $\mathrm{mP}$ (meio piano), pp (pianíssimo).

Implementação da tecnologia de Vivências Musicais

Considerando os passos adotados, a implementação da tecnologia propriamente dita se deu no campo, junto dos idosos portadores de DP, somente quando as etapas anteriores haviam sido cumpridas - ou seja, a tecnologia desenhada testada e revista, e a definição da amostra, composta de 12 participantes, a ser acompanhada no decorrer da implementação. Assim, as vivências musicais se realizaram por dois semestres do ano de 2007, com freqüência de duas horas semanais, sempre em um mesmo local planejado para a prática das vivências no campus da UESB/DS.

\section{Procedimentos de avaliação de} vivências musicais

Cada idoso participante da amostra foi submetido individualmente à aplicação do instrumento de avaliação da voz falada e da voz cantada, antes e depois da implementação da tecnologia de vivências musicais. Os dados foram pareados em antes e depois, para a avaliação comparativa do desempenho de cada um, diante da prática de vivências musicais desenvolvidas ao longo dos dois semestres. 
Seguem os procedimentos de aplicação do instrumento de avaliação:

1. Para avaliação da emissão vocal quanto à amplitude do volume da voz falada/canta$\mathrm{da}$, foi solicitado que cada idoso respondesse a um questionário com perguntas-padrão relativas a informações sociodemográficas e de identidade sociocultural (nome, endereço, idade, sexo, estilo musical de preferência, entre outros). Em outro momento foi solicitada a execução da canção "Mariquinha foi embora”. Essa canção, vivenciada anteriormente, é intercalada de trechos recitativos, e proporciona a comparação entre as curvas melódicas da fala às da canção. A análise da qualidade vocal fez parte da avaliação perceptivo-auditiva, com a aferição subjetiva da voz exigindo somente o ouvido humano como instrumento de avaliação. Chama-se de dinâmica o grau de intensidade (volume, força) com o qual determinado som é emitido. Entre diversas formas de representar a dinâmica, foi adotada a mais usual em música para definir os padrões de amplitude do volume, a saber: $\mathrm{mF}$ (meio forte) indica uma voz com sonoridade ampla em toda a sua extensão; P (piano) indica uma voz fraca, com baixa intensidade, suave e branda; pp (pianíssimo) indica uma voz muito baixa com pouca expressão. Para avaliar o ritmo da fala e do canto, era solicitado que cada idoso recitasse o provérbio popular: "Água mole em pedra dura, tanto bate até que fura", seguindo uma pulsação fixa de apoio, utilizando a figura rítmica da colcheia como unidade de tempo, variando apenas o andamento. O idoso falava o texto acompanhando as variações de velocidade da pulsa- ção, o que permitia classificar o ritmo da sua voz falada em regular, lento ou muito lento. Para avaliação do ritmo do canto, foi solicitado que cada idoso cantasse uma canção de livre escolha, seguindo uma pulsação rítmica marcada e fixa, alternando apenas a velocidade da marcação rítmica escolhida.

2. Com o objetivo de avaliar a dinâmica respiratória com base no número de notas musicais cantadas a uma só inspiração e articulação nos vocalizes, foi solicitado que cada idoso emitisse a seqüência da escala musical ascendente e descendente, no mesmo tom apresentado pelo teclado, iniciando-se em dó 3 para as mulheres e dó 2 para os homens, primeiramente em direção às freqüências agudas e, em seguida, em direção às graves, sempre de acordo com a escala musical (ascendente e descendente). A instrução dada a cada sujeito foi que emitisse cada nota até o limite. Em seguida, contava-se o número total de notas atingidas para obter a média de sons articulados, considerando o padrão de regularidade do total de 15 notas cantadas a uma só inspiração, tendo como base a figura rítmica da semínima, já que a execução dessa seqüência melódica com notas musicais pode ser realizada com um mínimo de esforço. Oito notas cantadas caracterizam um movimento irregular no padrão respiratório, observando-se o nível de esforço exigido para a emissão. O maior grau de comprometimento poderá ser identificado com o padrão dois, que equivale ao mínimo de cinco notas cantadas a uma só inspiração, significando diminuição na atividade respiratória. ${ }^{17}$ 
A avaliação da qualidade vocal foi obtida por meio de um teclado Yamaha. Para verificar a articulação nos vocalizes, foram utilizadas seqüências de notas compondo intervalos de segundas e terças (a exemplo de dó-ré e dó-mi) e quartas e quintas (a exemplo de dó-fá e dó-sol).

3. Para avaliação da performance vocal associada ao desenvolvimento da postura na emissão da voz falada/cantada e articulação nos vocalizes, foi sugerido ao idoso que interpretasse canções de livre escolha, sendo orientado a desativar excessos de contração da musculatura posterior do pescoço, procedimento que contribuiria para a diminuição da tensão muscular de braços e pernas, aspectos comumente observados ao portador de DP. O idoso foi orientado, partindo da compreensão de que o enrijecimento ou encolhimento do tronco diminuiria o potencial da voz e a capacidade respiratória. A performance vocal é uma atividade prática e a aplicação de canções e vocalises permite a decodificação dos sons em sílabas, formando uma estrutura que pôde ser inteligível, acessível e menos estressante para a compreensão da emissão da voz humana. Essa análise também fez parte da avaliação perceptivo-auditiva, com a aferição subjetiva da voz exigindo somente o ouvido humano como instrumento de avaliação.
O teste foi aplicado sempre por um profissional licenciado em música, considerando o aspecto subjetivo e específico dessa avaliação e utilizando como recursos o teclado, o microsystem e os instrumentos de percussão.

\section{Cuidados éticos com os participantes da pesquisa}

O projeto foi submetido e aprovado pelo Comitê de Ética em Pesquisa da Universidade Federal de Santa Catarina/UFSC, cujos documentos se encontram arquivados sob o protocolo no 350/2005. Todos os procedimentos de respeito humano para com os participantes da pesquisa foram cumpridos segundo diretrizes da Resolução no 196/96 do CNS do Ministério da Saúde. ${ }^{18}$

\section{RESULTADOS E DISCUSSÃO}

A amostra estudada se constituiu de uma casuística de 12 idosos portadores de DP, nove homens e três mulheres, os quais se submeteram à tecnologia de vivências musicais por dois semestres de 2007 e avaliações devidas antes e depois da experiência, nos aspectos do desempenho da voz falada e cantada. 
Quadro 1 - Avaliação pré e pós-desenvolvimento da Tecnologia Assistiva de Vivências Musicais junto a idosos portadores de Doença de Parkinson quanto à emissão vocal, considerando volume e ritmo de voz falada e cantada. Jequié - BA, 2007.

\begin{tabular}{|c|c|c|c|c|c|}
\hline Idoso & Avaliação & $\begin{array}{l}\text { Amplitude do } \\
\text { volume da voz } \\
\text { falada }\end{array}$ & $\begin{array}{c}\text { Amplitude do } \\
\text { volume da voz } \\
\text { cantada }\end{array}$ & $\begin{array}{c}\text { Ritmo da } \\
\text { fala }\end{array}$ & $\begin{array}{c}\text { Ritmo do } \\
\text { canto }\end{array}$ \\
\hline \multirow[t]{2}{*}{01} & Pré & 0 & 0 & 0 & 0 \\
\hline & Pós & 0 & 0 & 0 & 0 \\
\hline \multirow[t]{2}{*}{02} & Pré & 1 & 2 & 1 & 1 \\
\hline & Pós & 1 & 1 & 1 & 1 \\
\hline \multirow[t]{2}{*}{03} & Pré & 0 & 1 & 1 & 1 \\
\hline & Pós & 0 & 0 & 1 & 0 \\
\hline \multirow[t]{2}{*}{04} & Pré & 1 & 2 & 2 & 2 \\
\hline & Pós & 1 & 2 & 2 & 2 \\
\hline \multirow[t]{2}{*}{05} & Pré & 0 & 1 & 1 & 1 \\
\hline & Pós & 1 & 1 & 1 & 1 \\
\hline \multirow[t]{2}{*}{06} & Pré & 1 & 1 & 1 & 1 \\
\hline & Pós & 0 & 0 & 0 & 0 \\
\hline \multirow[t]{2}{*}{07} & Pré & 1 & 1 & 1 & 1 \\
\hline & Pós & 0 & 0 & 1 & 0 \\
\hline \multirow[t]{2}{*}{08} & Pré & 0 & 1 & 0 & 1 \\
\hline & Pós & 0 & 0 & 0 & 0 \\
\hline \multirow[t]{2}{*}{09} & Pré & 2 & 2 & 2 & 2 \\
\hline & Pós & 0 & 1 & 0 & 1 \\
\hline \multirow[t]{2}{*}{10} & Pré & 0 & 0 & 0 & 1 \\
\hline & Pós & 0 & 0 & 0 & 0 \\
\hline \multirow[t]{2}{*}{11} & Pré & 1 & 1 & 1 & 1 \\
\hline & Pós & 1 & 1 & 1 & 1 \\
\hline \multirow[t]{2}{*}{12} & Pré & 1 & 1 & 1 & 1 \\
\hline & Pós & 1 & 1 & 1 & 1 \\
\hline
\end{tabular}

Legenda:

Avaliação da amplitude do volume da vOz falada/cantada: $0=\mathrm{mF}$ (meio forte)

$1=\mathrm{P} \quad$ (piano)

$2=p p($ pianíssimo $)$
Avaliação do ritmo do canto e da fala:

$0=$ regular

$1=$ lento

$2=$ muito lento
Os resultados expressos no quadro 1 apontam para uma melhoria na efetividade da emissão vocal, falada ou cantada, com a prática das vivências musicais em sete idosos. Apenas um idoso teve diminuição da amplitude do volume da emissão de voz fa- lada. Os demais quatro mantiveram-se em todos os aspectos de volume e ritmo de emissão da voz, seja falada ou cantada, significando a manutenção do estado de emissão vocal mesmo passada a evolução de um ano da doença. 
Observando-se os dados de ritmo da fala e do canto, a maioria dos idosos na medida pré-experiência de vivências musicais apresentava um ritmo lento ou muito lento. Isto poderia estar relacionado com a evolução da doença nos idosos, uma vez que a DP desencadeia alterações vocais, acarretando maior agravamento na coordenação motora da fala, tais como dificuldade respiratória, diminuição do suporte aéreo e menor amplitude de movimento da musculatura facial, dificultando ou mesmo impedindo a produção vocal. ${ }^{19}$ Contudo, observou-se que na medida pós-experiência, esses idosos apresentaram melhora no ritmo da fala e do canto, o que indica estar relacionado com a prática das vivências musicais.

Assim como o ritmo, as alterações no volume de voz estão relacionadas com o comprometimento do aparelho da fonação, como rouquidão e qualidade do sopro, com evidente redução de intensidade, além de imprecisão articulatória e gama tonal reduzida, associado ainda ao processo de envelhecimento vocal e a cronicidade da doença. ${ }^{19}$ Também foram observadas nos dados tais alterações de volume da voz. Entretanto, na medida pós-experiência de vivências musicais, observou-se que esses idosos mantiveram seu quadro e outros apresentaram melhora no volume da voz, concluindo que a adoção de tal tecnologia representa um recurso preventivo de evolução precoce da DP.

Os dados de avaliação de padrões respiratórios (quadro 2) fundamentaram-se na prática de respiração vivenciada por meio de atividades musicais, como a articulação de notas cantadas a uma só inspiração utilizando a pulsação da semínima (figura rítmica) como unidade de tempo, e a execução de vocalizes para expansão das zonas de ressonância. $\mathrm{O}$ padrão de regularidade refere-se à respiração nasal com um ritmo regular, considerando que as alterações físicas (de posturas) e emocionais contribuem para a apresentação de um padrão respiratório alterado.

Ao avaliar a dinâmica respiratória dos idosos na etapa anterior à experiência, observase que quanto ao número de notas cantadas a uma só inspiração, a maioria se encontrava em um padrão respiratório irregular (amplitude torácica maior que a abdominal durante a inspiração), o que foi visto também na articulação de vocalises, a qual apresentava um padrão baixo ou muito baixo. Mesmo após a prática de vivências musicais, o número de idosos que obteve melhoria na dinâmica respiratória foi mínimo; no entanto, ter mantido o quadro representa um fato importante, uma vez que não houve progressão dos comprometimentos do aparelho fonador na evolução de um ano da doença.

Esses comprometimentos estão diretamente relacionados com a incompetência glótica freqüente no portador de DP, pois a adução glótica e o fluxo aéreo são responsáveis pelo controle da pressão aérea subglótica. Com a evolução da doença, as disfunções no campo laríngeo de desequilibrio de pressão provocam uma limitação do suporte respiratório e conseqüente redução da intensidade vocal $O$ equilibrio entre o suporte respiratório e os mecanismos laríngeos permite a manutenção da vibração das pregas vocais, e o aumento da intensidade vocal depende diretamente do aumento da pressão aérea subglótica., 
Quadro 2 - Avaliação pré e pós-desenvolvimento da Tecnologia Assistiva de Vivências Musicais junto a idosos portadores de Doença de Parkinson quanto à dinâmica respiratória, com base em número de notas musicais cantadas a uma só inspiração, articulação nos vocalises e desenvolvimento de exercícios associados às mesmas. Jequié/BA, 2007.

\begin{tabular}{|c|c|c|c|c|}
\hline Idoso & Avaliação & $\begin{array}{c}\mathrm{N}^{\mathrm{o}} \text { de notas } \\
\text { musicais cantadas a } \\
\text { uma só inspiração }\end{array}$ & $\begin{array}{l}\text { Articulação } \\
\text { nos vocalizes }\end{array}$ & $\begin{array}{c}\text { Desenvolvimento de } \\
\text { exercícios associados } \\
\text { a vocalizes }\end{array}$ \\
\hline \multirow[t]{2}{*}{01} & Pré & 1 & 0 & 0 \\
\hline & Pós & 1 & 0 & 0 \\
\hline \multirow[t]{2}{*}{02} & Pré & 1 & 1 & 1 \\
\hline & Pós & 1 & 1 & 1 \\
\hline \multirow[t]{2}{*}{03} & Pré & 1 & 0 & 0 \\
\hline & Pós & 1 & 0 & 0 \\
\hline \multirow[t]{2}{*}{04} & Pré & 2 & 2 & 1 \\
\hline & Pós & 2 & 2 & 2 \\
\hline \multirow[t]{2}{*}{05} & Pré & 1 & 1 & 1 \\
\hline & Pós & 1 & 1 & 1 \\
\hline \multirow[t]{2}{*}{06} & Pré & 1 & 0 & 0 \\
\hline & Pós & 0 & 0 & 1 \\
\hline \multirow[t]{2}{*}{07} & Pré & 1 & 1 & 0 \\
\hline & Pós & 1 & 0 & 1 \\
\hline \multirow[t]{2}{*}{08} & Pré & 1 & 0 & 0 \\
\hline & Pós & 0 & 0 & 0 \\
\hline \multirow[t]{2}{*}{09} & Pré & 2 & 2 & 2 \\
\hline & Pós & 2 & 1 & 1 \\
\hline \multirow[t]{2}{*}{10} & Pré & 1 & 0 & 0 \\
\hline & Pós & 1 & 0 & 1 \\
\hline \multirow[t]{2}{*}{11} & Pré & 1 & 1 & 1 \\
\hline & Pós & 1 & 1 & 1 \\
\hline \multirow[t]{2}{*}{12} & Pré & 1 & 1 & 1 \\
\hline & Pós & 1 & 1 & 1 \\
\hline
\end{tabular}

- Número de notas cantadas a uma só respiração: $0=>15$ notas $1=8$ notas $2=<$ de 5 notas Unidade de tempo $=$ semínima* Articulação nos vocalizes $0=$ regular $1=$ baixa $2=$ muito baixa

Exercícios respiratórios associados a vocalizes $0=$ normal $1=$ tenso $2=$ muito tenso

- Em relação a unidade de tempo utilizada como referência faze-se necessário compreender a representação das figuras rítmicas e seus valores proporcionais.

As figuras rítmicas representadas abaixo nos ajudam a compreender a unidade de tempo utilizada. A semibreve vale quatro tempos, a mínima vale dois tempos que representa a metade da semibreve, e unidade de tempo utilizada na avaliação foi a semínima que equivale e metade da mínima ou a $1 / 4$ da semibreve.

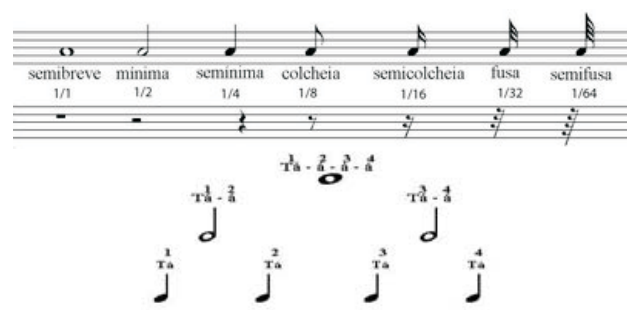


Quadro 3 - Avaliação pré e pós-desenvolvimento da Tecnologia Assistiva de Vivências Musicais junto a idosos portadores de Doença de Parkinson, segundo a performance vocal associada ao desenvolvimento da postura na emissão da voz falada/cantada e articulação nos vocalises. Jequié/BA, 2007.

\begin{tabular}{|c|c|c|c|}
\hline Idoso & Avaliação & $\begin{array}{l}\text { Desenvolvimento postural na } \\
\text { emissão voz falada/cantada }\end{array}$ & $\begin{array}{l}\text { Articulação nos } \\
\text { vocalizes }\end{array}$ \\
\hline \multirow[t]{2}{*}{01} & Pré & 0 & 0 \\
\hline & Pós & 0 & 0 \\
\hline \multirow[t]{2}{*}{02} & Pré & 1 & 1 \\
\hline & Pós & 1 & 1 \\
\hline \multirow[t]{2}{*}{03} & Pré & 1 & 1 \\
\hline & Pós & 1 & 0 \\
\hline \multirow[t]{2}{*}{04} & Pré & 1 & 2 \\
\hline & Pós & 2 & 2 \\
\hline \multirow[t]{2}{*}{05} & Pré & 1 & 1 \\
\hline & Pós & 1 & 1 \\
\hline \multirow[t]{2}{*}{06} & Pré & 0 & 1 \\
\hline & Pós & 1 & 0 \\
\hline \multirow[t]{2}{*}{07} & Pré & 1 & 1 \\
\hline & Pós & 0 & 0 \\
\hline \multirow[t]{2}{*}{08} & Pré & 1 & 1 \\
\hline & Pós & 0 & 0 \\
\hline \multirow[t]{2}{*}{09} & Pré & 2 & 2 \\
\hline & Pós & 1 & 1 \\
\hline \multirow[t]{2}{*}{10} & Pré & 1 & 0 \\
\hline & Pós & 1 & 0 \\
\hline \multirow[t]{2}{*}{11} & Pré & 1 & 1 \\
\hline & Pós & 1 & 1 \\
\hline \multirow[t]{2}{*}{12} & Pré & 1 & 1 \\
\hline & Pós & 1 & 1 \\
\hline
\end{tabular}

Legenda:

$0=$ regular

$1=$ tenso

$2=$ muito tenso

O desenvolvimento da performance vocal no sistema da voz cantada visa a uma série de relações estabelecidas entre a convivência do indivíduo e sua relação com a música.

Neste sentido, uma postura equilibrada com um movimento coordenado na hora de tocar um instrumento ou cantar pode ser obtida, quando isso faz parte do universo cotidiano do indivíduo, aspecto não apresentado pelos sujeitos da pesquisa no início da implementação da tecnologia. Embora exista a busca de uma atitude física eficiente para um bom desempenho da emissão vocal, não é possível uma abordagem direta de uma imagem predeterminada de "postura certa". Cada 
corpo é único e com características próprias, podendo ou não se encaixar em um padrão estereotipado. Corroborando os princípios da técnica, foram considerados aspectos subjetivos para utilização do padrão regular, tenso e muito tenso, considerando tempo de evolução da DP, a maneira de andar, sentar, levantar e a performance durante a emissão da vOz cantada/ falada. Portanto, a performance torna visíveis os atores, definem-se identidades e ajuda na construção de auto-imagem.

Considerando todos os aspectos formais e subjetivos da avaliação, no que tange à convivência e história musical e a condição física e de postura de cada idoso participante, observouse, conforme o quadro 3, que a condição da postura na emissão da voz cantada foi qualificada como tensa na maioria dos idosos. Apenas um apresentou padrão de normalidade. Contudo, na medida pós-experiência de vivências musicais, observou-se uma evolução positiva de tensa para normal em três pacientes. Os demais, em sua maioria, mantiveram seu estado anterior. Já na articulação dos vocalises, observou-se que dois pacientes apresentaram articulação normal, considerando os movimentos necessários a hábitos motores corretos de emissão da vOz cantada, partindo de movimentos primários posteriormente reorganizados de acordo com as condições físicas de cada um. Cinco idosos demonstraram avanço na segunda etapa da avaliação, presumivelmente beneficiados pela prática da tecnologia aplicada.

Ao avaliar a postura dos idosos no momento da emissão da voz, constatou-se maior tendência de postura tensa (postura desconfortável, com certa rigidez e tensão mus- cular) justificáveis, de uma parte, por possível timidez, e de outra, por corresponder às alterações de posturas características do portador de DP. O desenvolvimento de uma fixação de postura anormal caracterizada tipicamente numa postura flexionada ou recurvada (cifótica) está relacionado com os músculos flexores e adutores que se tornam seletivamente mais contraídos tanto nos membros superiores quanto nos inferiores, associado ainda à rigidez do tronco, ${ }^{2}$ interferindo assim na performance vocal do indivíduo.

As melhoras, por menores que parecessem, observadas durante as práticas de vivências musicais junto aos idosos com DP, se deveram ao desvio da tensão, quando o foco da tarefa era a expressão artística, afastando padrões e normas predeterminadas de comunicação. O desafio de cantar uma canção/ vocalise afastava a insegurança, tensão e alteração no comportamento motor, e fazia com que o paciente desviasse a atenção de sua limitação, ao se concentrar sobre o que ouvia e cantava, e não sobre a maneira como se processava a emissão do som. Tal fato corrobora o estudo anteriormente realizado. ${ }^{20}$

A DP desencadeia uma série de crises emocionais a seu portador, devido às perdas que nunca sofreram antes e que estão associadas à patologia, além do processo de envelhecimento acompanhado de cronicidade. Afeta sobremaneira o paciente, ocasionando desvios na auto-imagem e auto-estima, pela falta da manutenção de atitude positiva acerca de si mesmo e de aceitar-se, o que exige esforço orientado para a reestruturação da vida. Por isso estudos continuados são ainda 
demandados, tendo em vista encontrar tecnologias leves, assistivas/cuidadas e outros recursos que beneficiem o viver cotidiano em condição de cronicidade dos idosos portadores de DP.

\section{CONSIDERAÇÕES FINAIS}

A implementação de tecnologia assistiva pelas vivências musicais durante dois semestres se mostrou eficiente pelos resultados obtidos nos parâmetros avaliados:

a) a maioria dos portadores de DP apresentou melhorias na emissão vocal, tanto em volume quanto em ritmo; e outros conservaram o estado anterior, significando que não perderam esse atributo, apesar de terem passado pela evolução de um ano da doença;

b) alguns portadores demonstraram melhorias na dinâmica respiratória, principalmente no aumento do número de notas cantadas em uma só inspiração e articulação nos vocalises. Contudo, muitos se mantiveram no seu estado anterior, não só nas duas categorias citadas anteriormente, como também no desenvolvimento de exercícios associados aos vocalises, considerando a não-progressão do quadro, passado o tempo de um ano da doença;

c) alguns idosos demonstraram melhorias na performance vocal, seja do desenvolvimento de postura na emissão da voz, seja na articulação dos vocalises. Já a maioria se conservou no seu estado anterior, significando a não-progressão da doença durante o período de um ano. O preparo técnico vocal realizado nessas vivências certamente influiu nas emissões, favo- recendo a projeção tanto na voz cantada como na voz falada.

Dos resultados obtidos, pôde-se inferir que os idosos participantes da tecnologia assistiva de vivências musicais se beneficiaram no sentido de se manterem incluídos socialmente com seus familiares acompanhantes, ao se descobrirem com capacidades e possibilidades dentro dos limites que sua doença impunha, participando dessas atividades musicais. Os resultados positivos obtidos no presente estudo estão delimitados a uma casuística de 12 participantes acompanhados por apenas um ano, levando-nos a admitir a necessidade e importância de testes, em larga escala, de aplicação da dita tecnologia na assistência aos portadores de Doença de Parkinson, tendo em vista a manutenção da melhor qualidade de vida e inserção social dos envolvidos. A verificação de sua viabilidade técnica e financeira nos programas sociais e de saúde é também de fundamental importância.

\section{NOTAS}

\footnotetext{
Docente do Curso de Enfermagem da UESB/ DS.Coordenadora do subprojeto do TAIP: Tecnologia assistiva por meio de vivencias musicais na recuperação vocal de idosos portadores de Doença de Parkinson.

b,c Docentes de Enfermagem da UESB/DS. Membros da equipe de pesquisadores.

d Analista Universitária da UESB - Coordenadora Técnica de Música. Mestranda em Ciências Sociais - PUC/SP

Docente de Enfermagem da UFSC/PEN - Florianópolis, SC. Coordenadora do projeto TAIP, convenio: UFSC/ PEN/ GESPI x UESB/DS/ GREPE, Ref. 2183/05, subvencionado pela FINEP - Financiadora de Estudos e Projetos, Ministério da Ciência e Tecnologia (Chamada Pública MCT/FINEP/AT - Tecnologias Assistivas - 09/2005).

f Licenciada em Música. Bolsista ATP/CNPq, 2006-2008.

g.h Bolsistas de Iniciação científica da UESB. Financiada pela FAPESB-BAHIA
} 


\section{REFERÊNCIAS}

1. Reis T. Doença de Parkinson: pacientes, familiares e cuidadores. Santa Maria: Pallotti; 2004.

2. O' Sullivan SOB. Doença de Parkinson. In: O' Sullivan SOB, Schimitz. Fisioterapia: avaliação e tratamento. São Paulo: Manole; 2006. p.747-75.

3. Limongi JCP. Conhecendo melhor a Doença de Parkinson. São Paulo: Plexus; 2001.

4. Bhatia S, Gupta A. Impairments in activities of daily living in Parkinson's disease: implications for management. Archive NeuroRehabilitation 2003; 18(3): 209-14.

5. Azevedo LL, Cardoso F, Reis C. Analise acústica da prosódia em mulheres com doença de Parkinson: comparação com controles normais. Arq Neuropsiquiatr 2003 dez; 61(4): 999-1003.

6. Dias AE, João CPL. Tratamento dos distúrbios da vOz na doença de Parkinson: o método Lee Silverman. Arq Neuropsiquiatr 2003 mar; 61(1): 61-6.

7. Mosquera JJM, Stobaus CD, Jesus SN. Autoimagem, auto-estima e auto-realização na universidade. Revista Electrónica de la Federación española de Asociaciones de Psicologia 2005;10(3): 1-12

8. Vieillard S. Emoções musicais. Revista Viver Mente \& Cérebro 2005 jun; ano XIII(149): 52-7.

9. Good M. A comparison of the effects of jaw relaxation and music on postoperative pain. J Nurs Res 1995 Jan./Feb.; 44(1): 52-7.

10. Leinig CE. Tratado de Musicoterapia. São Paulo: Sobral; 1997.259 p.

11. Schaller K. Acordes Curativos. Revista Viver Mente\&Cérebro 2005 jun; (149): 64-9.
12. Kim Y. The effect of improvisation-assisted desensitization, and music-assisted progressive muscle relaxation and imagery on reducing pianists' music performance anxiety. Journal Music Therapy 2008 June.; 45(2): 165-91.

13. Zimmerman L, et al. Effects of music in patients who had chronic cancer pain. J Nurs Res 1989: 11(3): 298-309.

14. Fonseca KC, et al. Credibilidade e efeitos da música como modalidade terapêutica em saúde. Revista eletrônica de Enfermagem. 2006; 08(03): 398-403. Disponível em: URL: htpp:/ / www.fen.ufg.br/revista/revista83/v8n3a10.htm

15. Merhy EE. Saúde: a cartografia do trabalho vivo. 3. ed São Paulo: Hucitec; 2002.

16. Fundação Instituto Brasileiro de Geografia e Estatística - IBGE. Brasil em números, 2004. Disponível em: URL: http:// www.ibge.gov.br.

17. Rocha TF, Amaral FP, Hanayama EM. Extensão vocal de idosos coralistas e não coralistas. Revista CEFAC : actualizac'a Po $_{0}$ cientiifica em fonoaudiologia 2007 abr./jun.; 9(2): 248-54.

18. Resolução nº 196 Conselho Nacional de Saúde 1996 out 10. Estabelece normas sobre pesquisas envolvendo seres humanos. Diário Oficial da União, [1996 out. 10].

19. Silveira DN, Brasolloto AG. Reabilitação vocal em pacientes com Doença de Parkinson: fatores interferentes. Pro Fono 2005 maio/ago;17(2): 241-50.

20. Corte B, Ludovici NP. A musicoterapia como tratamento coadjuvante à Doença de Parkinson. Revista de Psicogerontologia Tiempo 2007; 20:9. 
1 